\title{
RASA1-Related Parkes Weber Syndrome in a Neonate
}

\section{Hong Ryul Koh, Yeon Kyung Lee, Sun Young Ko, Son Moon Shin, and Byoung-Hee Han*}

Departments of Pediatrics and Radiology*, Cheil General Hospital \& Women's Healthcare Center, Dankook University College of Medicine, Seoul, Korea

\section{ABSTRACT}

Parkes Weber syndrome is a rare congenital vascular anomaly, related to the RAS p21 protein activator 1 (RASA1) gene. It is characterized by capillary cutaneous malformations, bony and soft tissue hyperplasia, and multiple arteriovenous fistulas throughout the affected upper or lower extremity. These arteriovenous fistulas can be associated with life-threatening complications such as bleeding, thrombosis, and high output heart failure. In this report, we present a neonate who had a disproportionately hypertrophied left upper limb with port-wine stain, dystrophy of the left humerus, and hypertrophy of the left clavicle on X-ray, and arteriovenous malformation and massive dilatation of the left subclavian artery on magnetic resonance angiography. Exome sequencing analysis revealed a novel heterozygous splicing mutation $(\mathrm{c} .1776+2 \mathrm{~T}>\mathrm{A})$ in the $R A S A 1$ gene. To the best of our knowledge, this report is the first case of RASAl-related Parkes Weber syndrome in Korea.

Key Words: Parkes Weber, RASAl, Neonate

\section{INTRODUCTION}

Parkes Weber syndrome (PWS) is a rare congenital vascular anomaly, comprising of capillary, venous, lymphatic, and arteriovenous malformations (AVMs), characterized by hypertrophy of the affected extremity ${ }^{1}$. Capillary malformation (CM) is a slow-flow vascular malformation that forms on the skin as a pink to red macular lesion, otherwise known as a port-wine stain ${ }^{2)}$. If this port-wine stain is accompanied by hypertrophy of the affected limb, the differential diagnoses to be considered include PWS, Klippel-Trenaunay syndrome, and Proteus syndrome $\mathrm{e}^{3,4)}$. CM-AVM is a rare condition of atypical CMs associated with fast-flow AVMs and multiple arteriovenous fistulas (AVFs) anywhere in the body ${ }^{4,5}$. Among these CMAVMs, PWS includes capillary cutaneous malformation, limb hypertrophy, and multiple AVFs of the affected extremity. These AVFs can lead to abnormal bleeding, thrombosis, and heart failure ${ }^{6,7)}$. Some cases of PWS and CM-AVMs have the same genetic abnormality due to mutations in the RAS p21 protein activator 1 (RASA1) gene, which affects the development of the vascular system ${ }^{8,9}$.

We report here, a case of PWS with the identification of a novel RASAl splicing mutation.
Received: 31 May 2018

Revised: 18 July 2018

Accepted: 30 July 2018

Correspondence to: Yeon Kyung Lee Department of Pediatrics, Cheil General Hospital \& Women's Healthcare Center, Dankook University College of Medicine, 17 Seoae-ro 1gil, Jung-gu, Seoul 04619, Korea

Tel: +82-2-2000-7107

Fax: +82-2-2000-7789

E-mail: ykleeped@hanmail.net

Copyright(c)

By Korean Society of Neonatology.

All right reserved.

This is an Open-Access article distributed under the terms of the Creative Commons Attribution Non-Commercial License (http://creativecommons.org/licenses/ by-nc/4.0), which permits unrestricted non-commercial use, distribution, and reproduction in any medium, provided the original work is properly cited. 


\section{CASE REPORT}

A male infant was admitted to our neonatal intensive care unit for evaluation of severe enlargement and violaceous discoloration of the left upper extremity. His mother was 35 years old and her obstetric history was gravida 3 , para 2 , living 1 . There was no familial history of vascular disease or hemangioma. The patient was born at $39^{+1}$ weeks of gestation by repeated Cesarean section. At the time of birth, his Apgar score was 8 at one minute and at 5 minutes. His birth weight was 3,515 g (75th to 90th percentile), height was $49 \mathrm{~cm}$ (75th to 90th percentile), and the head circumference was $35.5 \mathrm{~cm}$ (above 90th percentile). His vital signs were stable, with a blood pressure of $55 / 33 \mathrm{~mm} \mathrm{Hg}$, heart rate of 152 beats/min, respiratory rate of 27 beats/min, and body temperature of $36.5^{\circ} \mathrm{C}$.

On physical examination, the infant had hypertrophy of the left upper extremity. The length of the left arm was $17 \mathrm{~cm}, 2 \mathrm{~cm}$ longer than the right arm, and the middle circumference of the left upper arm was $15 \mathrm{~cm}$, compared to $10 \mathrm{~cm}$ of the right arm. The left arm movements occurred freely in the horizontal plane, but there was hardly any mobility in the vertical plane. On the affected area, the port-wine stain was observed and the violaceous color became darker during crying and activity (Figure 1). We felt local warmth with bruit over the left shoulder and upper arm.

The radiograph of the left arm showed dystrophy of the left humerus with soft tissue swelling (Figure 2). An echocardiogram revealed normal cardiac function and structure except a huge left subclavian artery. On an ultrasound of the left upper arm, high velocity waveform with increased diastolic flow due to an

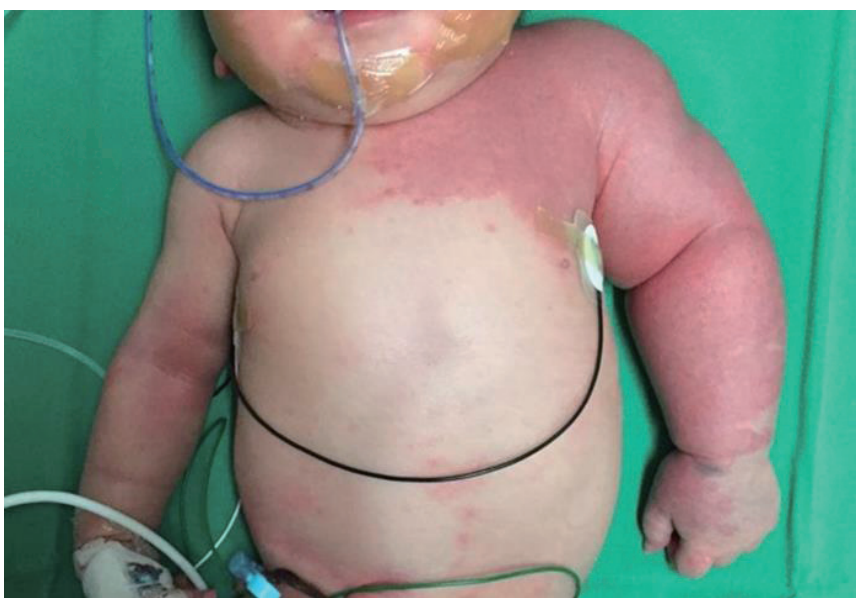

Figure 1. Photograph showing an asymmetric hypertrophy of the left upper extremity with an extensive geographic port-wine stain. arteriovenous shunt was observed in the upper arm around the humeral head (Figure 3). Magnetic resonance imaging (MRI) and magnetic resonance angiogram (MRA) showed engorged left subclavian and axillary arteries, and their branches included the left circumflex humeral arteries, arteries of the forearm, and muscular branches (Figure 4). Chromosomal analysis

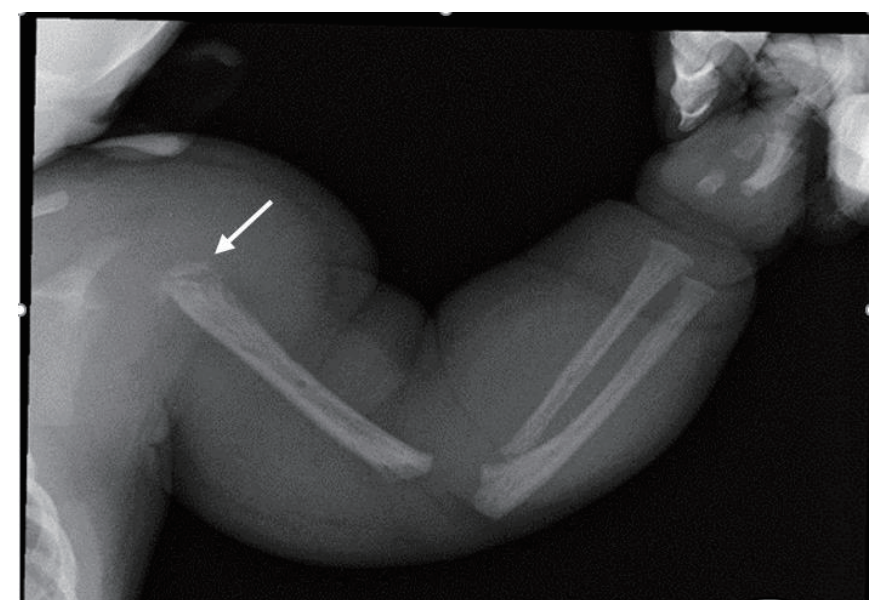

Figure 2. Radiograph of the left arm shows dystrophy of the left humerus (arrow) and diffuse soft tissue swelling of the left arm and shoulder.

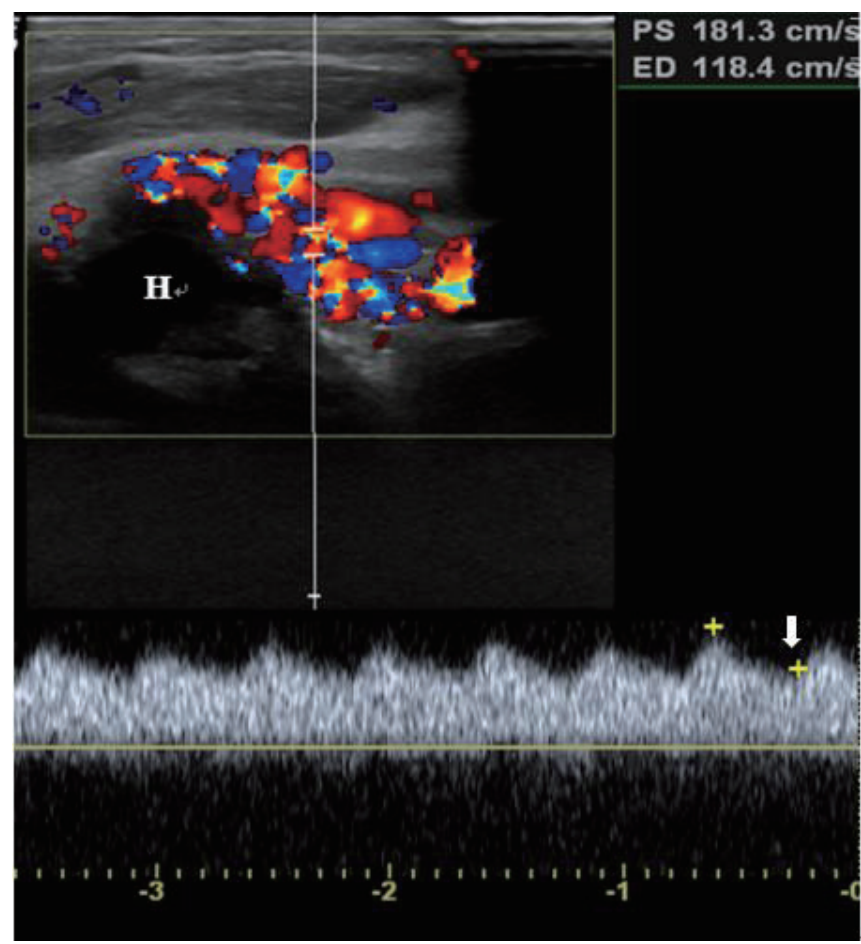

Figure 3. Doppler ultrasound of the left arm demonstrates a high velocity waveform $(181.3 \mathrm{~cm} / \mathrm{sec})$ with increased diastolic flow (arrow) due to an arteriovenous shunt in the upper arm around the humeral head $(\mathrm{H})$. 
revealed a normal male karyotype of $46, \mathrm{XY}$ without structural abnormalities. We performed a molecular genetic study to identify the underlying genetic cause for the limb hypertrophy with a cutaneous CM. Diagnostic exome sequencing test was performed. A novel heterozygous splicing mutation

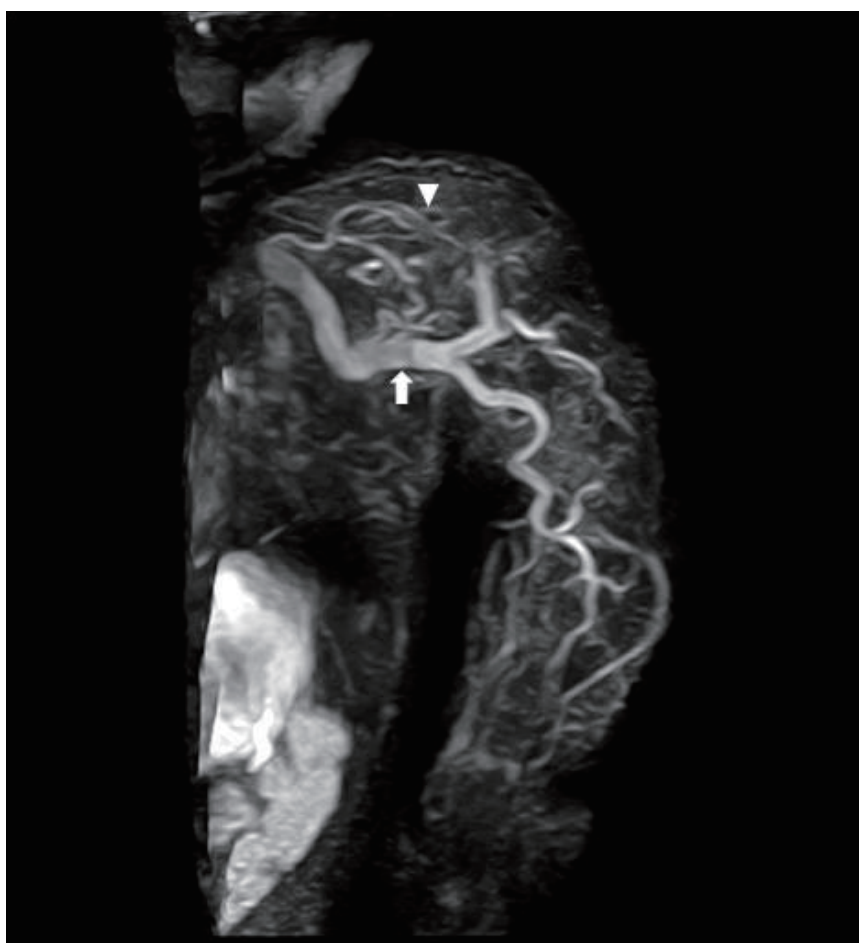

Figure 4. Magnetic resonance angiogram of the left arm shows engorged left subclavian, and axillary arteries (arrow) with their branches including left circumflex humeral arteries, arteries of forearm, and muscular branches (arrowhead).
NG_011650.1 (NM_002890.2):c.1776+2T>A was identified in the boundary between exon 13 and intron 13 of the RASA1 gene in the patient. There was no mutation of the gene in his parents and elder brother (Figure 5). Further medical examination included brain ultrasound, abdominal ultrasound, metabolic workup, blood-clotting tests, ophthalmologic examination, and otoacoustic emission, all of which were normal. On the 13th day of hospitalization, he was discharged without hemodynamic changes and diagnosed with PWS. Written informed consent was obtained from the patient's parents for publication of this case report, including images.

\section{DISCUSSION}

PWS is a rare congenital vascular anomaly characterized by $\mathrm{CM}$, fast-flow arteriovenous shunt, and hypertrophy of the limb. It was first reported by Frederic Parkes Weber in $1907^{1)}$. Its exact prevalence is unknown, but approximately 50 patients including three neonates have been reported until $2015^{10,11)}$. CM is the most common vascular anomaly, which is present at birth and found in $0.3 \%$ of the affected infants ${ }^{2}$. It comprises of increased and enlarged capillaries with increased blood flow near the skin, and appears as a pink to red macular lesion, often referred to as a port-wine stain ${ }^{6)}$. Unlike the capillary hemangiomas, skin lesions of CM tend to progress with time ${ }^{4)}$.

CM-AVM is a rare complex vascular disorder, first described by Eerola et al. ${ }^{5)}$ in 2003. Its clinical features are characterized

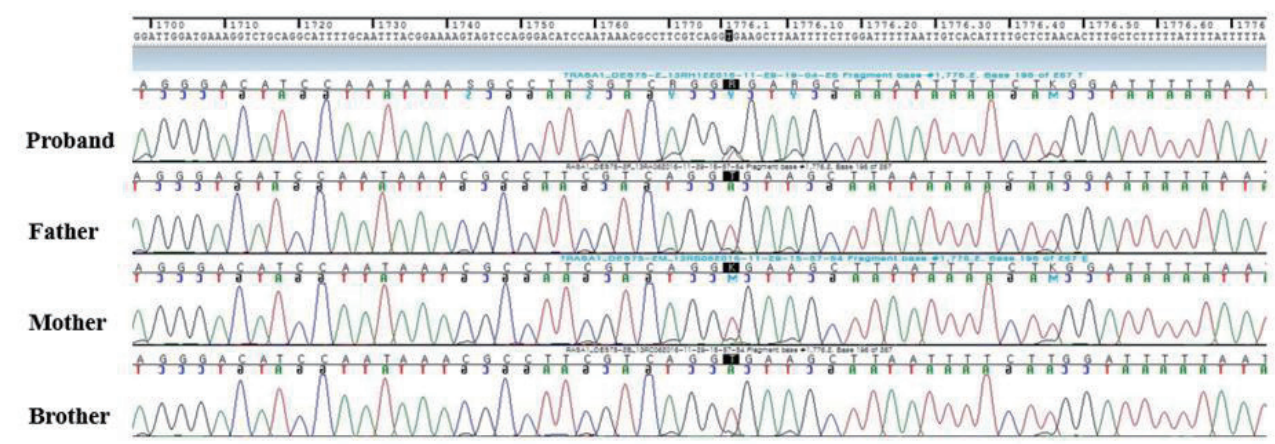

Figure 5. Chromatogram of the patient (proband) and family members for the RAS p21 protein activator 1 (RASA1) gene. Genetic analysis showing the sequence of exon 13 and intron 13 of RASA1, where the mutation was detected in the patient. The mutation is $\mathrm{c} .1776+2 \mathrm{~T}>\mathrm{A}$. His parents and brother had no mutation of the gene. 
by atypical multifocal CMs, which are associated with fast-flow AVFs. AVMs and AVFs involve an abnormal connection between arteries and veins that affect blood circulation ${ }^{6}$. They can occur anywhere in the body including cutaneous, subcutaneous, intramuscular, intraosseous, and cerebral regions ${ }^{3,4)}$. The clinical symptoms depend on the location and extent of AVMs. These AVFs can lead to severe complications, such as abnormal bleeding, thrombosis, and heart failure ${ }^{6,11)}$. Such high-flow AVMs tend to appear during infancy, but some occur later in childhood $^{3,4)}$. If there are CMs and limb hypertrophy without defined AVM in an infant, it is difficult to differentiate among PWS, Klippel Trenaunay syndrome (KTS), and Proteus syndrome ${ }^{8)}$. KTS is a congenital vascular anomaly, consisting of capillary, venous, and lymphatic malformations, with soft tissue and bony hypertrophy of the affected limb. The cutaneous lesions of KTS are smaller and darker, and the discrepancy in the limblength increases slowly compared to PWS. It is a pure low-flow vascular malformation, while PWS is characterized by highflow AVMs. KTS is associated with the phosphatidylinositol-4,5bisphosphate 3-kinase catalytic subunit alpha (PIK3CA) gene ${ }^{12)}$. PWS is often confused with KTS until AVMs and the genetic causes are proven. Proteus syndrome is a rare hamartomatous disorder, characterized by various cutaneous and subcutaneous lesions, including vascular malformations, lipomas, and hyperpigmented nevi in addition to hemihypertrophy. Unlike PWS, limb hypertrophy is mild at birth and worsens with age. Proteus syndrome is caused by mutations in the AKT serine/ threonine kinase 1 (AKT1) gene ${ }^{13)}$. PWS is a kind of CM-AVM, comprising limb hypertrophy with cutaneous capillary stain and multiple AVFs of the extremity. These AVFs can cause local warmth with thrill of the affected limb. In addition, varicose veins and lymphedema may coexist due to venous and lymphatic malformations ${ }^{4)}$. In our case, the patient had a pink to red macular lesion and disproportionately severe hypertrophy of the left extremity and local warmth with bruit was felt in the affected limb since birth.

The diagnosis of PWS is usually based on the clinical features described above. Diagnostic imaging is necessary to assess the location and extent of AVMs. Initial evaluation can be performed with Doppler-ultrasound for distinguishing fast-flow AVM from the slow-flow vascular malformation ${ }^{14)}$. Further anatomic details are obtained using MRI and MRA, which can reveal musculoskeletal abnormalities, as well as vascular malformations including engorged arteries, veins, capillaries, and flow voids ${ }^{12,15)}$.
Most cases of PWS are sporadic, although the syndrome might manifest an autosomal dominant inheritance pattern. Some cases of PWS are caused by a mutation in the RASAl gene ${ }^{8)}$. The $R A S A 1$ gene mutation was first identified as an aberrant gene in 2008, implicated in the development of $\mathrm{PWS}^{9)}$. This RASAl gene is located on chromosome 5 at the position 14.3 and codes for p120-RasGAP, which acts as a negative regulator of RET signaling and affects the G-protein signaling TC21 regulation pathway. The p120-RasGAP has an effect on cell growth, differentiation, and proliferation $^{16)}$. Mutations of the RASA1 gene affect CM-AVM and lead to manifestations of PWS, but it is unclear how these mutations affect variable phenotypes ${ }^{5,8}$. According to the National Center for Biotechnology Information (https://www.ncbi.nlm. nih.gov/clinvar/?term=RASA1[gene]), 49 mutations have been reported in the RASA1 gene-related to PWS with a pathogenic variant, and many of these (29/49) are untranslated region mutations as well as missense mutations. So far, there have been no reports of splicing mutations. In the patient presented here, we identified a novel heterozygous splicing mutation in the RASA1 gene.

There is no definite cure for PWS. The goal of treatment for PWS is to improve the patient's quality of life and treatment should be individualized according to the age and clinical features of the patient. Compressive stocking is mainly used as a palliative care for edema and venous ulceration. Invasive treatments such as embolization using a coil, stent-graft implantation, AVM resection, and amputation are considered when complications such as heart failure, venous ulceration, and aneurysm occur ${ }^{7,11,13)}$. Recently, sirolimus, a mammalian target of rapamycin (mTOR) inhibitor used for venous and lymphatic malformation, has been tried but its effect has not been proven yet $^{17)}$.

In the present case, we identified a novel RASA1 heterozygous splicing mutation in a patient with PWS presenting a severely hypertrophied left upper limb with port-wine stain and AVM. To our knowledge, this is the first case of RASA1-related PWS in Korea.

\section{CONFLICT OF INTEREST}

No potential conflict of interest relevant to this article was reported. 


\section{REFERENCES}

1. Parkes Weber F. Angioma: formation in connection with hypertrophy of limbs and hemi-hypertrophy. Br J Dermatol 1907;19;231-5.

2. Maguiness SM, Liang MG. Management of capillary malformations. Clin Plast Surg 2011;38:65-73.

3. Nozaki T, Nosaka S, Miyazaki O, Makidono A, Yamamoto A, Niwa T, et al. Syndromes associated with vascular tumors and malformations: a pictorial review. Radiographics 2013;33:17595.

4. Enjolras O, Chapot R, Merland JJ. Vascular anomalies and the growth of limbs: a review. J Pediatr Orthop B 2004;13:349-57.

5. Eerola I, Boon LM, Mulliken JB, Burrows PE, Dompmartin A, Watanabe S, et al. Capillary malformation-arteriovenous malformation, a new clinical and genetic disorder caused by RASA1 mutations. Am J Hum Genet 2003;73:1240-9.

6. Gloviczki P, Duncan A, Kalra M, Oderich G, Ricotta J, Bower T, et al. Vascular malformations: an update. Perspect Vasc Surg Endovasc Ther 2009;21:133-48.

7. Adekanmi AJ, Schernthaner RE, Lammer J. Parkes Weber syndrome: a rare vascular malformation-imaging and the usefulness of intravascular intervention. Internet J Radiol 2015; 18:1-7. https://doi.org/10.5580/IJRA.24813.

8. Hershkovitz D, Bergman R, Sprecher E. A novel mutation in RASA1 causes capillary malformation and limb enlargement. Arch Dermatol Res 2008;300:385-8.

9. Revencu N, Boon LM, Mulliken JB, Enjolras O, Cordisco MR, Burrows PE, et al. Parkes Weber syndrome, vein of Galen ane- urysmal malformation, and other fast-flow vascular anomalies are caused by RASA1 mutations. Hum Mutat 2008;29: 959-65.

10. Behr GG, Liberman L, Compton J, Garzon MC, Morel KD, Lauren CT, et al. CM-AVM syndrome in a neonate: case report and treatment with a novel flow reduction strategy. Vasc Cell 2012;4:19.

11. Banzic I, Brankovic M, Maksimovic Z, Davidovic L, Markovic M, Rancic Z. Parkes Weber syndrome-diagnostic and management paradigms: a systematic review. Phlebology 2017;32:371-83.

12. Ziyeh S, Spreer J, Rossler J, Strecker R, Hochmuth A, Schumacher M, et al. Parkes Weber or Klippel-Trenaunay syndrome? Non-invasive diagnosis with MR projection angiography. Eur Radiol 2004;14:2025-9.

13. Jamis-Dow CA, Turner J, Biesecker LG, Choyke PL. Radiologic manifestations of Proteus syndrome. Radiographics 2004;24: 1051-68.

14. Paltiel HJ, Burrows PE, Kozakewich HP, Zurakowski D, Mulliken JB. Soft-tissue vascular anomalies: utility of US for diagnosis. Radiology 2000;214:747-54.

15. Lobo-Mueller E, Amaral JG, Babyn PS, Wang Q, John P. Complex combined vascular malformations and vascular malformation syndromes affecting the extremities in children. Semin Musculoskelet Radiol 2009;13:255-76.

16. Kulkarni SV, Gish G, van der Geer P, Henkemeyer M, Pawson T. Role of p120 Ras-GAP in directed cell movement. J Cell Biol 2000;149:457-70.

17. Triana P, Dore M, Cerezo VN, Cervantes M, Sanchez AV, Ferrero MM, et al. Sirolimus in the treatment of vascular anomalies. Eur J Pediatr Surg 2017;27:86-90. 